\title{
Edição do poema Recordação de Monte Alegre: uma das canções dos caminhos de Eulálio Motta
}

\author{
Editing the poem Remembrance of Monte Alegre: one of the songs of the paths of Eulalio \\ Motta \\ Taylane Vieira dos Santos* \\ Universidade Estadual de Feira de Santana, Feira de Santana, Bahia, Brasil \\ Patrício Nunes Barreiros** \\ Universidade Estadual de Feira de Santana, Feira de Santana, Bahia, Brasil
}

\begin{abstract}
Resumo: O presente trabalho tem como objetivo apresentar a edição do poema Recordações de Monte Alegre, de autoria do escritor baiano Eulálio de Miranda Motta. Esse poema integra o livro inédito Canções do meu caminho ( $3^{2}$ Edição), esboçado pelo autor e conservado em documentos do seu acervo. A edição do livro é objeto da dissertação de mestrado de Taylane Vieira dos Santos, que está sendo desenvolvida no Programa de Pós-Graduação em Estudos Literários da UEFS. O poema Recordação de Monte Alegre contém seis testemunhos, variando entre manuscritos, datiloscritos e impressos. Por conta da pluralidade dos testemunhos o que se apresenta nesse artigo é uma edição crítico-genética, com o intuito de estabelecer o texto a partir do cotejamento das variantes.
\end{abstract}

Palavras chave: Eulálio Motta. Canções de meu caminho. Edição Crítico-genética.

\begin{abstract}
The present work aims to present the edition of the poem Recordaçôes de Monte Alegre, authored by the Bahian writer Eulálio de Miranda Motta. This poem integrates the unpublished book Songs of My Path (3rd Edition), drafted by the author and preserved in documents in his collection. The book's edition is the subject the dissertation of Taylane Vieira dos Santos, which is being developed in the UEFS Graduate Program in Literary Studies. The poem Recordações de Monte Alegre contains six testimonies, ranging from manuscripts, typewritten and printed. Because of the plurality of testimonies, what is presented in this article is a critical-genetic edition, in order to establish the text from the comparison of variants.
\end{abstract}

Keywords: Eulálio Motta. Canções de meu caminho. Critical-genetic Edition.

\section{INTRODUÇÃO}

Esse estudo faz parte de uma pesquisa de mestrado, desenvolvida no âmbito do Programa de Pós-Graduação em Estudos Literários e está relacionada ao Projeto de pesquisa Edição das obras inéditas de Eulálio Motta, coordenado pelo professor Patrício Nunes Barreiros, na UEFS ${ }^{1}$. Segundo Barreiros (2009), o escritor baiano Eulálio de Miranda Motta organizou nove livros que não chegaram a ser publicados, permanecendo inéditos no seu acervo. Entre essas obras inéditos encontra-se a terceira edição de um livro de poesia intitulado Cancõoes de meu caminho. É justamente a edição desse livro que é o objeto de estudo da dissertação de mestrado Taylane Vieria dos Santos, ainda em andamento.

A terceira edição de Canções de meu caminho contém 86 poemas preservados em manuscritos, datiloscritos e impressos (livros, panfletos e jornais). Para a terceira edição do livro, Eulálio Motta incluiu dezessete poemas inéditos. Ele esboçou um sumário para o livro listando os poemas que pretendia incluir na coletânea. Além disso, em muitos manuscritos

*Estudante de Mestrado do Programa de Pós-Graduação em Estudos Literários da Universidade Estadual de Feira de Santana, bolsitas CPES/CNPq. Email: tayvieira25@hotmail.com. Orientador.

**Professor da Universidade Estadual de Feira de Santana, doutor em Letras e Linguística. Email: patricio@uefs.com.

${ }^{1} \mathrm{O}$ projeto é financiado pela Fapesb e pelo CNPq. 
avulsos e em impressos em forma de panfletos, ele inseriu notas declarando que os textos fariam parte do livro.

Figura 1 - Recorte do manuscrito Trovas antológicas.

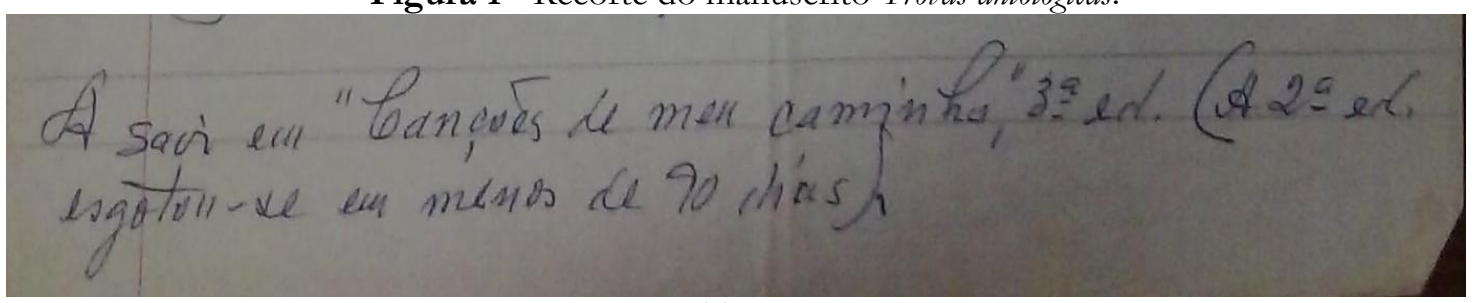

Fonte: Recorte de um manuscrito avulso do poema Trovas antológicas.

A maior parte dos poemas possuem mais de um testemunhos com variantes autorais. Isso permite estudar o percurso criativo do texto e esboçar um aparato crítico-genético.

Como forma de demonstrar o andamento da pesquisa, o artigo em questão teve como objetivo apresentar a edição de um dos poemas que compõe a obra Cançôes de meu caminho ( $3^{\mathrm{a}}$ edição), intitulado Recordação de Monte Alegre. A pesquisa está subsidiada pelo método da Crítica Textual (SPINA, 1994; CAMBRAIA, 2005; BORGES, 2003; PRIEGO, 1997), da Crítica Genética (GRÉSILLON, 1994; WILLEMART, 2008) e dos estudos acerca dos acervos de escritores e sua contribuição para o universo literário baiano e brasileiro (RETTENMAIER, 2008; BORDINI, 2001; BARREIROS, 2015; ARTIÈRES, 1998).

\section{O POETA EULÁLIO MOTTÁ}

Eulálio de Miranda Motta nasceu em 15 de abril de 1907 numa vila do município de Mundo Novo, interior da Bahia, chamada Alto Bonito. O escritor viveu a sua infância entre o Arraial de Alto Bonito, a Fazenda Vaca Parida de seu avô e a Fazenda Morro Alto, lugares recorrentes nos versos eulalianos e que deixaram profundas marcas em seu imaginário.

Aos dezessete anos, Eulálio Motta foi viver em Monte Alegre, hoje Mairí, onde trabalhou como balconista numa farmácia e deu continuidade aos estudos iniciados na vila Alto Bonito. Em Mairí, conheceu uma jovem chamada Edy que se tornou a musa inspiradora de seus versos.

Em 1926, Eulálio Motta ingressou no Ginásio Ipiranga, na cidade de Salvador, com o objetivo de se preparar para ingressar na universidade. O período que viveu em Salvador contribuiu para a sua formação intelectual e para definir o seu perfil de escritor, pois ao chegar à capital, ele fez amizades com diversos escritores, passando a frequentar reuniões para discutir literatura. Em Salvador, conseguiu publicar seus sonetos em revistas como $A$ Luva, A Renascença, Vanguarda, nos jornais O Imparcial, Caderno da Babia, Diário de Notícias e $A$ Tarde. Em 1929, Eulálio Motta ingressou na Faculdade de Medicina da Bahia, concluindo o curso de Farmácia em 1933. No mesmo ano, decidiu voltar a residir em Mundo Novo, na Fazenda Morro Alto e se dedicou à pecuária, à literatura, ao jornalismo e, esporadicamente, atuava como farmacêutico. Apesar de ter dedicado grande parte de sua vida à literatura, Eulálio Motta publicou apenas três livros de poesias: Ilusões que passaram... em 1931, Alma enferma em 1933 e Canções de meu caminho em duas edições, a primeira edição em 1948 e a segunda em 1983.

Em sua trajetória enquanto escritor, Eulálio Motta passou por diversas fases, adotando diferentes estilos e temáticas. A maior parte de sua poesia versa sobre o amor não correspondido, a ação implacável do tempo, a memória da infância e as festas populares que fizeram parte da sua infância e que continuam presentes na cultura nordestina. 


\section{A IMPORTÂNCIA DO ACERVO PARA A PESQUISA}

A pesquisa em acervo de escritores se faz cada vez mais necessária para que seja possível trazer a lume uma literatura que se encontra fora do alcance dos leitores. A filologia, por meio da edição de textos, cumpre esse papel de escrutinar as velhas arcas dos escritores e promover o encontro do texto literário com os leitores. Desse modo, contribui-se para revitalizar a memória literária baiana e brasileira, além de ampliar as possibilidades de pesquisas no âmbito da crítica literária.

Segundo Miguel Rettenmaier (2008), o trabalho com a pesquisa em acervo literário visa revitalizar o passado em um novo presente, diretamente influenciado pelas pistas, pelos "resíduos" ou pelas "pegadas" deixadas por determinado autor. Nesse sentido, atualiza-se a história, recupera-se o passado, presentifica-se e revitaliza-se o que fora silenciosamente arquivado ou guardado em dependências particulares. De acordo com Bordini (2001, p. 31):

A memória, nesse sentido, deixa de ser compreendida como uma capacidade mnemônica particular, individual ou familiar, e passa a ser uma consciência mais coletiva, preocupada em lembrar o que já foi sustentada em monumentos e documentos, que precisa preservar para manter-se autoconsciente do que é (BORDINI, 2001, p. 31).

O acervo traz à tona aquilo que não aparece no texto publicado, permitindo um profícuo diálogo entre os diversos elementos que compõem o laboratório do escritor: anotações de leituras, esboços, rascunhos, projetos, a correspondência, as notas marginais, etc. No momento em que o escritor produz uma obra, esse livro não é composto apenas de seus textos, por trás de cada obra existe uma infinidade de contextos relacionados a ela. Nesse sentido Rettenmaier (2008, p. 144) diz o seguinte:

A literatura não é feita apenas de obras literárias, pois há um mundo no entorno de cada livro. Da mesma forma, um livro não é feito apenas de seu texto. Há uma plêiade de textos ao seu redor, ao lado e abaixo dele. Os manuscritos e planejamentos do autor são parte desses "subtextos", desses textos subterrâneos, sepultados nas gavetas, esquecidos em caixas que sobreviveram à lixeira, seja pelo cuidado dos herdeiros, seja pelo descuido (consciente ou inconsciente) do escritor. Esses textos, que, por algum motivo, foram desvalorizados ao não se tornarem públicos e definitivos, essas anotações que revelam os impulsos da mente criativa do escritor, contraditoriamente, ingressando em um acervo literário, tornam-se relíquias. Além de terem em si a magia da presença física do autor, que cruzou o papel com a palma da mão e registrou-se com sua letra a cada linha traçada, os manuscritos têm a capacidade de permitir releituras das obras (RETTENMAIER, 2008, p. 144).

A maior parte das pesquisas literárias está relacionada ao estudo do texto em si. Esse olhar restrito para com o texto publicado faz com que o pesquisador deixe de perceber e explorar os elementos que estão ao redor do texto e que enriquecerão a sua abordagem. Tendo acesso a esses textos "subterrâneos" como destaca Rettenmaier (2008), é que o pesquisador amplia s possibilidades de interpretar a obra.

Quando se dispõe de um acervo organizado pelo próprio autor e que conta com os elementos do seu laboratório (manuscritos, rascunhos, esboços, etc.), as possibilidades de leitura da obra literária torna-se muito mais profícuo. É isso que ocorre com o acervo do escritor Eulálio Motta. A documentação acumulada por ele durante mais de sessenta anos permite vislumbrar o processo de criação de sua obra literária, sua memória individual e até mesmo a memória coletiva porque permite vislumbrar como o escritor se relacionou com outros escritores, autoridades políticas, amigos e familiares.

O acervo de Eulálio Motta é constituído de documentos acumulados por ele entre os anos de 1923 e 1988. É composto de materiais de diferentes naturezas, incluindo rascunhos e esboços de obras inacabadas, manuscritos e datiloscritos de textos éditos e inéditos, diários, cadernos de anotações diversas, correspondências, fotografias, documentos de identificação, 
diplomas, esboços de projetos editoriais, coleções de jornais e panfletos, instrumentos de trabalho como a sua máquina de escrever.

Segundo Barreiros (2015), pela natureza da documentação, esse rico acervo pode ser compreendido como um projeto autobiográfico, revelando-se como um caleidoscópio de onde se projetam diversas imagens do escritor. Independente da condição social e do ofício do sujeito, os documentos que compõem os acervos pessoais trazem sempre as marcas da subjetividade e "[...] uma intenção autobiográfica" (ARTIÈRES, 1998, p. 11). Assim, os acervos são considerados como marcas de si.

Os documentos que constituem o acervo eulaliano foram descritos e catalogados por Barreiros (2007a). Segue abaixo a descrição do acervo:

a) 15 cadernos manuscritos, contendo textos literários inéditos, rascunhos de cartas, anotações diárias do cotidiano, projetos, etc;

b) 88 correspondências, incluindo cartas ativas e passivas, cartões de diversos tipos e telegramas;

c) 39 datiloscritos de textos literários;

d) 9 diplomas;

e) 11 documentos de identificação pessoal;

f) 870 fotografias identificadas e não identificadas;

g) 88 livros que integravam a biblioteca do autor;

h) 6 folhetos de cordel;

i) 1129 exemplares de panfletos;

j) 49 exemplares de jornal;

k) 68 manuscritos dispersos;

l) Uma coleção de 32 cédulas de dinheiro antigo;

m) A máquina de escrever de Eulálio Motta.

O acervo de Eulálio Motta encontra-se sob a guarda de Patrício Nunes Barreiros e está depositado no Núcleo de Estudos Interdisciplinares em Humanidades Digitais, na sala 26 do Módulo Teórico, do Departamento de Letras e Artes da UEFS. Esse acervo tem possibilitado a edição das obras inéditas do escritor e favorecido o estudo do seu processo criativo, além disso, possibilita acompanhar a sua atividade intelectual e artística durante seis décadas, pois Eulálio Motta arquivou suas memórias e os fragmentos de sua produção literária. Segundo Barreiros (2009), dentre os documentos arquivados pelo escritor mundonovense, os cadernos destacam-se pela riqueza de informações e pela diversidade de uso que o escritor fez deles. Nos 15 cadernos que contam no acervo, foram escritos rascunhos de cartas, discursos políticos, anotações diárias, listas de palavras e endereços, anotações de leituras, crônicas, poesias, causos, além de conservarem os projetos editoriais de Eulálio Motta. A maior parte dos cadernos são projetos de livros que não foram publicados.

\section{A CRÍTICA TEXTUAL E O ESTUDO DA GÊNESE DO TEXTO: A CONSTITUIÇÃO DE UM APARATO CRÍTICO-GENÉTICO}

A Filologia, enquanto Crítica Textual tem contribuído, ao longo dos anos, para salvaguardar importantes documentos textuais, preservando a memória em todos os seus aspectos. Segundo Cambraia (2005, p. 19), a contribuição mais evidente e importante da crítica textual é:

[...] a recuperação do patrimônio cultural escrito de uma dada cultura. Assim como se restauram pinturas, esculturas, igrejas e diversos outros bens culturais da humanidade, a fim de que mantenham a forma dada por seu autor intelectual, igualmente restauram-se os livros em termos 
tanto físicos (recuperação da folha, da encadernação, da capa, etc.) quanto de seu conteúdo (recuperação dos textos) (CAMBRAIA, 2005, p.19).

Cambraia (2005) refere-se aos manuscritos como verdadeiros patrimônios que precisam ser recuperados e transmitidos para a preservação da memória. No momento em que se transmite um texto que foi retirado do anonimato, esse documento torna-se público ao leitor e dessa forma eterniza a sua preservação.

Na segunda metade do século XIX o método lachmanniano foi imprescindível para o desenvolvimento da Crítica textual. Nesse período, o editor lidava apenas com cópias de cópias procedentes de um original ausente, sendo assim, a tarefa da crítica textual era de reconstituir um texto que se aproximasse o mais possível do original perdido. Já no século $\mathrm{XX}$, um novo contexto começa a nascer, pois os filólogos passam a lidar com textos autorais, dessa forma não se busca mais o original perdido, mas a recuperação do "ânimo autoral" diante da pluralidade dos testemunhos autógrafos. Assim, o método proposto por Lachmann não foi banido, foi apenas questionado e adaptado para atender as novas realidades textuais da presente época. A Crítica Textual Moderna é descrita por Borges (2003, p. 44) da seguinte forma:

Considera que as relações entre o poeta, a obra e seu público (leitor) têm definido princípios críticos adequados à publicação das obras modernas. Esta nova postura que vem sendo adotada, tanto do ponto de vista teórico quanto metodológico, apresenta elementos que identificam a antiga Filologia com a emergente Crítica Genética, que agora vem sendo amalgamadas. Tem-se comumente apresentado sob a rubrica de "Edição Crítico-genética": edição crítica, quanto à obra publicada (fase editorial) e genética, por examinar os testemunhos de redação (BORGES, 2003, p. 44).

Nesse novo contexto, o filólogo lida com variantes autorais que, de acordo com Pérez Priego (1997, p. 33), "ocorre quando um autor introduz modificações num texto do qual já se extraiu alguma cópia ou simplesmente o corrige em uma nova fase redacional". As abordagens para com os textos literários deixam de ser meramente analíticas e passam a ser realizadas a partir de uma visão mais ampla e aprofundadas da obra literária. Esse novo olhar para o texto literário permitiu que os pesquisadores valorizassem os elementos paraliterários e paratextuais que elucidam o texto. Dessa forma, o objeto de estudo da literatura amplia-se para um corpus composto pela variedade de textualidades relacionadas à produção intelectual do escritor e de seus vestígios documentais.

A crítica genética começa a ascender nesse período em busca de contemplar os elementos que compõem o corpus marcado por sua pluralidade. Para os geneticistas, segundo Almuth Grésillon (1991, p. 9 e 11),

[...] não é o escrito final que está no centro de interesse, mas a escritura que se está fazendo, com suas infinitas dependências, com suas pertinências, bem como com suas impertinências. Não é a psicologia do autor nem a biografia da obra que importaria narrar, mas é um antetexto, com o conjunto das marcas conservadas, que se deve estabelecer. A partir de então, o geneticista, assumindo sua própria subjetividade (portanto sem procurar imitar a do escritor), construirá hipóteses sobre a trajetória escritural do processo em questão (GRÉSILLON, 1991, p. 9 e 11).

A partir dos estudos da gênese do texto, o editor consegue perceber as inconstâncias da identidade do escritor, a forma como ele pensou o texto ou a obra e que em alguns casos as versões anteriores não condizem com a versão final. A maior parte dos testemunhos de Eulálio Motta apresentam emendas, rasuras, acréscimos, demonstrando o seu processo criativo. Características que permitem que o editor debruce-se sobre cada testemunho de forma minuciosa e analise a sua gênese.

Quando o editor depara-se com um texto com mais de um testemunho (politestemunhal), ele pode decidir estabelecer o texto crítico seguindo uma tendência 
lachmanniana, primando pelo texto único, ou decidir estabelecer o texto valorizando as variantes, construindo um aparato de variantes, organizando-as em ordem cronológica e interpretá-las à luz da Crítica Genética. Nesse caso, prima-se por uma edição crítico-genética que, segundo Borges (20012, p. 60), é "Uma edição crítica em uma perspectiva genética (crítico-genética) é uma prática editorial que concilia duas metodologias afins no campo da Filologia: a crítica textual e a crítica genética".

A título de ilustração apresentaremos a seguir um exemplo de edição crítico-genética do poema Recordação de Monte Alegre.

\section{A EDIÇÃo}

Trata-se de um poema de tom nostálgico, no qual o escritor recorda com carinho o lugar onde passou parte de sua adolescência e conheceu a sua amada, a jovem Edy. Destaca nomes de pessoas que fizeram parte da sua vida, ressalta que, apesar dos anos que se passaram, a cidade ainda conserva certas características do tempo da adolescência do poeta e sinaliza para a mudança do nome da cidade que, atualmente, é chamada de Mairí e, segundo Eulálio Motta, não evoca mais a beleza dos seus montes.

O poema dispõe de seis testemunhos: três impressos, dois datiloscritos e um manuscrito.

\subsection{TIPO DE EDIÇÃO}

O tipo de edição empregado procura estabelecer o texto, considerando a pluralidade de testemunhos com suas variantes e registra o percurso traçado pelo autor na construção do texto, ou seja, tratar-se de uma edição crítico-genética. Para o exemplo de edição que ora apresentamos, destacamos os seguintes critérios:

a) Descreve-se todos os testemunhos;

b) Para cada testemunho atribui-se um código para orientar a estrutura do aparato;

c) Analisa-se as variantes;

d) Justifica-se a escolha do texto de base;

e) O texto crítico é apresentado da seguinte forma:

(i) As linhas são numeradas de 5 em 5 à margem esquerda;

(ii) $\mathrm{O}$ aparato à margem esquerda corresponde a cada linha do texto, sendo sinalizadas as variantes, em negrito, de cada um dos testemunhos indicados por meio do código previamente estabelecido na descrição dos testemunhos;

(iii) $\mathrm{O}$ aparato apresenta as variantes em ordem cronológica;

(iv) Utilizou-se (s.r.) para indicar "sem reticências" e (s.v.) para indicar "sem vírgula";

(v) Manteve-se o uso de maiúsculas e a pontuação;

(vi) Correções ortográficas foram sinalizadas no aparto.

f) Foram utilizados os seguintes operadores genéticos para registrar o movimento de escritura do texto: \{\}$/ \backslash$ substituição por sobreposição, na relação \{substituído\} / substituto $\backslash$.

\subsubsection{Descrição física dos testemunhos}

\section{RMP}

Panfleto Impresso, sem data, em tinta azul com nota de rodapé que traz a seguinte indicação "DO LIVRO: "Luz̧es do Crepuisculo", inédito. / "A SAIR EM "Canções do meu 
caminho" $2^{a}$ edição. Além disso, há no panfleto a opinião de Jorge Amado e uma nota sobre a mudança de nome da cidade de Monte Alegre para Mairí.

\section{RML1}

MOTTA, Eulálio de Miranda. Recordações de Monte Alegre. In: FERNANDES, Aparício (Org.). Anuário de poetas do Brasil: 1982. Rio de Janeiro: Folha Carioca, 1982, p. 151.

Impresso em tinta preta, com 32 linhas. A página encontra-se em bom estado de conservação. $O$ título está centralizado na altura da página, em caixa alta.

\section{RMD1}

Cópia carbono de datiloscrito da segunda edição do livro Canções do meu scaminho, em tinta preta, com 38 linhas. A folha encontra-se em bom estado de conservação. No ângulo direito e superior consta o número do fólio. O título está centralizado na altura do fólio, em caixa alta e sublinhado por duas linhas. O texto encontra-se em dois fólios.

\section{RMD2}

Cópia carbono de datiloscrito da segunda edição do livro Canções do meu caminho, em tinta preta, com 38 linhas. A folha se encontra em um bom estado de conservação. Não consta explícito o número do fólio. O título está centralizado na altura do fólio, em caixa alta e sublinhado por duas linhas.

\section{RML2}

MOTTA, Eulálio. Canções do meu caminho. 2. ed. [s.l.]: [s.n.], [1983], p. 21-22.

Impresso em tinta preta, com 38 linhas. A folha se encontra em um bom estado de conservação. Na parte inferior e central da folha consta o número da página. O título está centralizado na altura da página, em caixa alta e em negrito.

\section{RMM}

Manuscrito no caderno Canções do meu caminho, texto em tinta azul, a numeração encontra-se na margem superior esquerda do fólio e o título está localizado na margem superior no centro do fólio. A folha encontra-se em bom estado de conservação e o texto contém apenas algumas pequenas rasuras.

\subsubsection{Seleção do texto de base}

Tomou-se como texto de base o texto RMM, por ser o último testemunho escrito do próprio punho do escritor. 
84

ISSN 1415 - 8973

Figura 2 - Manuscrito do poema Recordações de Monte Alegre

42 Recordac,ao de Monte Alegrie...

Nonte da Santa biruz du Monte Alegre! toonteurplo-te de longe com uma vontarle enorme de te ver de perto para recordaceab: de quando te vi pela primeina vez, ha mais de meio seculo, em utha sexta-qeira da paixao! Porso na tua imutabilidade: és o mesmo monte, com as mesmas pedras

e curvas do caminho;

coin aguile mesmo "afismo das alluras". agnela mesma heleza de horizontes. Todavia,

Como tudo snudor, Monte Dlegre quenido! ate' teu prosme

gin já nas lecuhra mais o ten ngontes Fonte: Fac-símile do CCMC3 (f. 23v).

Revistas A Cor das Letras, v. 17, n.1, p. 77-89, 2016 
85

ISSN $1415-8973$

Figura 3 - Cont. do manuscrito do poema Recordações de Monte Alegre

49

que ján nav Lar leutrar teus peregrinos

mas thas sextas-Jeiras da jocuixad!

Becondar ís veres, é becu triste!

Gente querilla que se contheceu e gue ja nas existe!

toel. Olegairio Shascaren has... a toonllade eve pessoa...

D. Glaquira - anju em forma ce rucelterm e aguell encanto de menina que era Yvete e que for ecubora Tao ceporessa!

Ponto find en tal recordacas antes que venha à toma urna ilesá gin se tornamia

ince Tormento.".

nnin ha loucura..

minha ohsessas...

Fonte: Fac-símile do CCMC3 (f. 24r).

Revistas A Cor das Letras, v. 17, n.1, p. 77-89, 2016 


\subsubsection{Texto crítico com o aparato}

\section{RMM}

\section{RECORDAÇÃO DE MONTE ALEGRE...}

Monte da Santa Cruz do Monte Alegre!

Contemplo-te de longe

com uma vontade enorme

5 de te ver de perto

para recordação:

de quando te vi pela primeira vez,

há mais de meio século,

em uma sexta-feira da paixão!

10 Penso na tua imutabilidade:

és o mesmo monte,

com as mesmas pedras

e curvas do caminho;

com aquele mesmo "abismo das alturas"!

15 aquela mesma paisagem deslumbrante aquela mesma beleza de horizontes.

Todavia,

como tudo mudou, Monte Alegre querido! até teu nome

20 que já não lembra mais o teu monte

que já não faz lembrar

teus peregrinos

nas tuas sextas-feiras da paixão!

Recordar, às vezes,

25 é bem triste!

gente querida que se conheceu

e que já não existe!

Cel. Olegário Mascarenhas...

a bondade em pessoa...

30 D. Glafira - anjo em forma de mulher... e aquele encanto de menina que era Ivete e que foi embora tão depressa!

Ponto final em tal recordação

35 antes que venha à tona uma ilusão que se tornaria meu tormento... minha loucura... minha obsessão..

\section{RMP ENCONTRO COM A POESIA (1) \\ RML1 RMD1 RMD2 RML2 RMP RECORDAÇÃO DE MONTE ALEGRE (s.r.)}

RML1 RMD1 RMD2 RML2 RMP longe...

RML1 RMD1 RMD2 RML2 RMP perto,

RMP de quando te vi / pela primeira vez, RML1 RMD1 RMD2 vez (s.v.)

RML2 RMM ha RMM seculo,

RML1 RMD1 RMD2 RML2 Paixão. RMP Paixão...

RML1 RMD1 RMD2 RML2 caminho: RMP caminho..

RMD1 RMD2 RML2 RMM aquêle RML1 "abismo das alturas”, RMD1 RMD2 RML2 “abismo das alturas,” RMP “abismo das alturas..."

RML1 RMD1 RMD2 RML2 deslumbrante, RMP deslumbrante.. RML1 horizonte. RMP horizonte..

RML1 Até RMP nome (2) RMM $\{\mathrm{m}\} / \mathrm{n} \backslash \mathrm{o}\{\mathrm{n}\} / \mathrm{m} \backslash \mathrm{e}$ RML1 RMD1 RMD2 RML2 que já não lembra teu monte, RMP monte, RMM \{nome\}/monte $\backslash$

RML1 RMD1 RMD2 RML2 RMP que não faz lembrar teus peregrinos

RML1 RMD1 RMD2 RML2 RMP Paixão!

RMP Recordar, às vezes, é bem triste...

RML1 RMD1 RMD2 RML2 triste.

RML1 RMD1 RMD2 RML2 Gente

RML1 RMD1 RMD2 RML2 existe. RMP existe...

RMD1 RMD2 RML2 Cel (s.p.) RML1 RMD1 RMD2 RML2 RMP

Mascarenhas,

RML1 RMD1 RMD2 RML2 RMP pessoa.

RML1 RMD1 RMD2 RML2 mulher.

RML1 RMD1 RMD2 RML2 RMP E

RMP que era Ivete

RMP e que foi embora tão depressa!

RML1 RMD1 RMD2 RML2 RMP recordação...

RML1 RMD1 RMD2 RML2 RMP Antes

RMP EULÁLIO MOTTA

DO LIVRO: "Luzes do Crepúsculo", inédito.

A SAIR EM “Canções do meu caminho" $2^{a}$ edição.

(1) "Não seja modesto, sua poesia é da melhor qualidade, apenas você a escondeu de todos," - Jorge Amado.

(2) Nome atual de Monte Alegre, no âmbito federal - Mairí por lei da Assembléia Estadual, voltou o nome de Monte Alegre.

Ficou, assim, a cidade com dois nomes: na burocracia e na boca do povo. Na papeleta federal - Mairí, que pouca gente sabe o que significa. Na papeleta estadual - Monte Alegre, que todo mundo sabe o que é. (Monte Alegre da Bahia). 


\subsubsection{Análise das variantes}

Os testemunhos RML1, RMD1, RMD2, RML2, e RMM são dependentes, apresentando variações apenas na pontuação, no uso de maiúsculas e na grafia de algumas palavras. Trata-se, portanto, do mesmo texto sem variações substanciais. Entretanto, o testemunho RMP apresenta variações substanciais que se observa não apenas no pontuação e no uso maiúsculas. Nesse testemunho destaca-se o layout do poema, evidenciado pela disposição dos versos, a inserção de notas explicativas e, principalmente, por ter um título diferente.

No RMP o escritor apresenta um título e um subtítulo: Encontro com a poesia / Recordações de Monte Alegre. Considerando que Eulálio Motta conheceu a musa inspirada de suas poesias em Monte Alegre, faz sentido o título do RMP. Além disso, o desfecho do poema traz à tona a sua amada, uma ilusão que se tornaria seu tormento, sua loucura, sua obsessão.

No panfleto (RMP), destaca-se Encontro com a poesia e Recordações de Monte Alegre encontra-se em fonte mentor, como um subtítulo (Cf. Figura 3).

Figura 4 - Fragmento do panfleto

\section{ENCONTRO COM A POESIA (') RECORDAÇÃO DE MONTE ALEGRE}

Fonte: Panfleto de Eulálio Motta preservado no acervo do escritor.

O RMP foi publicado em forma de panfleto e serviu também para anunciar a publicação da segunda edição do livro Canções do meu caminho e exalta as qualidades da poesia de Eulálio Motta, ao transcrever a opinião de Jorge Amado acerca de seus versos. Na nota, Eulálio Motta informa ainda que o poema faz parte do livro inédito Luzes do crepúsculo, mas, no caderno em que o escritor passou a limpo os poemas que fariam parte desse livro, não consta o poema Recordaçoes de Monte Alegre.

Estamos diante de um poema que apresenta duas versões, uma para o panfleto e outra para o livro. Os testemunhos RML1, RMD1, RMD2, RML2, e RMM foram escritos com o intuito de serem publicados num livro e o RMP para o panfleto. O suporte, nesse caso, determinou as diferenças observadas nas disposição dos versos. Quanto ao título, o poeta abandonou a ideia de manter um título e um subtítulo, optando por Recordações de Monte Alegre.

A oscilação no uso de reticências e exclamações é algo que se observa na maioria dos poemas de Eulálio Motta com mais de um testemunho. Há uma tendência do poeta e se tornar menos reticente e optar pelas exclamações. Parece que, com o passar dos anos, Eulálio Motta, já não tinha tempo de ser reticente, era tempo de admirar o passado e de se nutrir intensamente das lembranças.

\section{CONSIDERAÇÕES FINAIS}

Como já foi dito anteriormente, o referente estudo é parte de uma pesquisa que lida com um corpus composto por 86 textos que integram o livro inédito Canções de meu caminho ( $3^{\mathrm{a}}$ edição). Os textos editados foram escritos entres 1928 a 1988, correspondendo a sessenta anos da produção literária de Eulálio Motta. Tratam-se, portanto, de uma obra que expressa as diversas fases e temáticas da poesia do escritor. Há uma diferença considerável entre a terceira edição e as outras duas edições publicadas respectivamente em 1948 e 1983. A 
terceira edição de Canções do meu caminho é uma coletânea que Eulálio Motta começou a organizar em 1983, logo após à publicação da segunda edição que se esgotou em menos de noventa dias.

O poema Recordação de Monte Alegre é emblemático porque revela um dos mais significativos episódios da vida de Eulálio Motta, o seu encontro com Edy, a musa inspirada de seus versos. O lirismo amoroso de Eulálio Motta está impregnado pela ausência/perda de sua amada. A cidade de Monte Alegra evoca as lembranças do amor adolescente e se tornou cenário de várias poesias do escritor mundonovense. Monte Alegre é onde se mantém viva a memória do amor adolescente.

A edição do poema exigiu a análise de todos os testemunhos e constatou que o as modificações feita $\mathrm{s}$ ao longo do tempo não são substancias, manifestando-se, principalmente, no uso da pontuação. Notou-se que, ao longo do tempo, Eulálio Motta foi abandonando as reticências em favor das exclamações. Essa substituição em Trata-se de uma edição que valoriza a gênese dos textos, exigindo o estudo minucioso de cada um dos testemunhos e suas variantes.

A edição crítico-genética mostrou-se adequada para o tipo de texto que estamos lidando porque permite observar as alterações que se processaram no texto ao logo do tempo e permitir que o leitor tenha acesso a um texto estabelecido a partir do método da Crítica Textual.

\section{REFERÊNCIAS}

ARTIERÈS, Philippe. Arquivar a própria vida. Estudos Históricos, Rio de Janeiro, v. 11, n. 21, p. 9-34, 1998.

BARREIROS, Patrício Nunes. O Pasquineiro da roça: a hiperedição dos panfletos de Eulálio Motta. Feira de Santana: UEFS Editora, 2015.

BARREIROS, Patrício Nunes. A oficina do escritor e os projetos editoriais de Eulálio de Miranda Motta. Cadernos do CNLF (CiFEFil), v. 13, 2009.

BARREIROS, Patrício Nunes. Cantos tristes, no cemitério da ilusão: edição dos sonetos de Eulálio de Miranda Motta. 346 f. Dissertação (Mestrado em Literatura e Diversidade Cultural) Departamento de Letras, Universidade Estadual de Feira de Santana, Feira de Santana, 2007a.

BORDINI, Maria da Glória. Memória literária e novas tecnologias. Cadernos do Centro de Pesquisas Literárias da PUCRS, v. 7, n. 2, jun. 2001.

CAMBRAIA, César Nardelli. Introdução à crítica textual. São Paulo: Martins Fontes, 2005.

GRÉSILLON, Almuth. Alguns Pontos sobre a História da Crítica Genética. Estudos Avançados 11(5), 1991.

MOTTA, Eulálio de Miranda. Cancões do meu caminho. 2. ed. [s.l.]: [s.e.], 1983.

PRIEGO, Miguel Angel Pérez. La edición de textos. Madrid: Síntesis, 1997.

RETTENMAIER, Miguel. Pesquisa literária e acervo: a maldição dos manuscritos. Revista do Programa de Pós-Graduação em Letras da Universidade de Passo Fundo, v. 4, n. 2, p. 137 145, jul./dez., 2008. 
SANTOS, Rosa Borges dos. A Filologia e seu objeto - diferentes perspectivas de estudo. In: Revista Philologus, n. 9. Rio de Janeiro: CiFEFiL, maio/ago. 2003. 